\title{
Antecedentes e historia del teatro comunitario argentino contemporáneo. Los inicios de un movimiento
}

\section{Background and History of Argentinean Community Theater. The Beginning of a Movement}

\author{
Clarisa Fernández \\ Universidad Nacional de La Plata \\ clarisafernandez@conicet.gov.ar
}

\section{Resumen:}

El presente trabajo recorre los orígenes del teatro comunitario argentino contemporáneo. Reconstruye las expresiones teatrales que pueden considerarse antecedentes de este teatro enmarcados en momentos históricos concretos, con el fin de reconfigurar un mapa de origen que sitúe a la práctica teatral comunitaria dentro de un proceso histórico donde el arte ha jugado un papel fundamental.

Palabras clave: teatro comunitario, origen, historia.

\begin{abstract}
:
This paper goes through the origins of contemporary Argentine Community Theater. It rebuilds theater forms that can be considered precedents of this theater, framed in specific historical moments, in order to reconfigure a source map where Community Theater practice can be placed within a historical process where art has played a key role.
\end{abstract}

Keywords: Community Theater, Origin, History. 


\section{Introducción}

El primer grupo de teatro comunitario argentino se conformó en el año 1983, con el surgimiento del grupo Catalinas Sur en el barrio porteño de La Boca. Pero ese inicio no es azaroso, sino que tiene raíces muy profundas que se nutren de experiencias teatrales latinoamericanas de la década del sesenta y posteriores. Si bien el teatro comunitario se ha desarrollado en el territorio argentino con características estéticas y organizativas propias, existieron en diversas partes del mundo otras expresiones teatrales que, por lo menos discursiva y organizativamente, comparten múltiples elementos con esta práctica argentina contemporánea.

\section{Revolución}

Marina Pianca (10) plantea una periodización de la actividad teatral que da lugar al surgimiento del llamado Nuevo Teatro ${ }^{1}$, a partir de lo que significó política y culturalmente la Revolución cubana (1959). Si bien la autora se encarga de aclarar que las raíces de este proceso son anteriores a esa fecha, escoge dividirlo en tres periodos con el fin de señalar sucesos concretos de la historia y articularlos con la actividad teatral de ese momento. Consideramos importante comprender el desarrollo de las expresiones culturales y artísticas en consonancia con procesos que se dan a nivel latinoamericano y nacional, para luego adentrarnos en su especificidad local.

La autora presenta un primer periodo (1959-1968) que estaría signado por el clima de agitación política, de urgencia e insurgencia, originado y abonado por la Revolución cubana. Identifica que en distintos países latinoamericanos proliferan grupos que progresivamente plantean la necesidad de dialogar y compartir experiencias, impulso que se concretizó en los primeros Festivales Nacionales de Teatro Universitario y Teatro de Aficionados. El segundo periodo (1968-1974) se caracterizaría por el cuestionamiento y modificación del paradigma teatral, en cuanto se pusieron en tensión sus estructuras organizativas, de producción y distribución. Aparece la metodología de la acción colectiva, la búsqueda e integración de un público popular y la formulación de un proyecto latinoamericano. Si bien en el tercer periodo (1974-1980) los cuestionamientos de la etapa anterior no cesaron, las represiones instauradas por las dictaduras en los países latinoamericanos mostraron diferencias irreconciliables entre los sectores de poder y los proyectos políticos que los colectivos artísticos que desafiaban a los cánones de la cultura elitista buscaban instaurar (Pianca 19-21).

La periodización que señala Pianca solo es un esquema que nos servirá de punto de partida para formular una cronología que nos permita, de forma analítica, compren-

1 Con el término Nuevo Teatro Marina Pianca se refiere a un movimiento teatral conformado por ciertos grupos que optaron por denominar su trabajo de esta forma, a partir de los festivales de teatro que surgieron a finales de la década del setenta en Cuba y Colombia. 
der el surgimiento del teatro comunitario y los nexos que lo unen tanto a las expresiones teatrales previas como a los procesos históricos.

\section{Momentos 50-60-75}

Fue entre los años 1930 y 1950 cuando se desarrolló con fuerza en el ámbito teatral argentino el movimiento de Teatro Independiente ${ }^{2}$, cuya postura era fuertemente desafiante a los circuitos oficiales del arte y la política. Este teatro nucleaba a grupos filodramáticos, anarquistas y socialistas, círculos católicos, clubes y colectividades que buscaban una novedad estética a través de la experimentación. Proliferaban las obras que reivindicaban a los autores nacionales y que acentuaban la finalidad educativa del teatro y la militancia (Seibel 33-7).

El teatro anarquista, que creció notablemente desde finales de los años veinte y se fue apagando hacia principios de los setenta, se caracterizaba por no tener una estética propia, sino por valerse de varias poéticas existentes. Con una estructura sencilla que recorría el melodrama y el drama realista con tintes didácticos, se centraba básicamente en su mensaje de oposición al Estado, a la Iglesia y al concepto de Dios. Resaltan como características del teatro libertario el lenguaje directo, la presentación didáctica, la apelación al público alienado, el rechazo al costumbrismo, y la superficialidad y la pretensión de "revolucionar" desde el escenario (Fos 203). Por otra parte, los teatros obreros como el Teatro Obrero de la CGT, los textiles, los tranviarios y otros gremios llevaron adelante producciones teatrales durante 1948 y 1955 (Seibel 291-407).

Para iniciar el recorrido que nos ubicará en la periodización señalada por Pianca, nos situaremos en la década del sesenta en Argentina, momento de ebullición de la cultura. Como una tendencia teatral emergente de esta década, las experiencias de vanguardia del Instituto Di Tella se caracterizaron por la radicalización en los lenguajes formales y por la redefinición de la noción de teatro. Determinados elementos de esta arte escénica se fusionaban con los de otras áreas de la cultura como la danza, las artes visuales o la música (Verzero 288). Por otra parte, el clima de marcada radicalización política debido a los efectos de la Revolución cubana contribuyó a la politización del ámbito artístico e intelectual. La figura del intelectual argentino comprometido con la transformación social se vio a su vez atravesada por el peronismo (Verzero 290), y fue durante estos años que surgieron grupos de teatro militante.

Verzero (290) ubica el origen del teatro militante en lo que Pianca denomina periodo transicional, marcado por las experiencias de vanguardia y la profundización de la crisis social. La necesidad de contar con ciertos espacios de militancia política y artística,

2 Leonidas Barleta es reconocido por los historiadores como el fundador del Teatro del Pueblo (1930). A este le siguen otros como Teatro IFT (1932), La Cortina (1937), La Máscara, Libre Teatro, Tinglado (1939), Fray Mocho (1951) y Teatro de los Independientes (1952). 
y de asociarse para intervenir políticamente fue crucial a partir de la segunda mitad de la década del sesenta; no se registraron continuidades de grupos que hayan surgido en este periodo luego de 1975. Dentro del teatro militante se incluyen las prácticas colectivas de intervención política que buscaban participar de las luchas sociales por medio de esta forma de expresión. Estos grupos se componían de jóvenes de diversa formación que no provenían necesariamente del ámbito teatral. Dado que el teatro militante -que en algunos casos estaba articulado con organizaciones o partidos de izquierda- perseguía fines político-sociales, la experiencia estética estaba al servicio del objetivo principal, que era transformar el sistema capitalista, hacer la revolución e instaurar el socialismo.

En el año 1969 se formaron los grupos Libre Teatro Libre (LTL) y Once al Sur. El primero, que se fundó en un departamento de la Universidad Nacional de Córdoba, proponía la exploración artística a través de la experiencia del teatro antropológico ${ }^{3}$ y los postulados de Erwin Piscator ${ }^{4}$. Su metodología de creación colectiva se combinaba con la militancia política en el Partido Revolucionario del Pueblo (PRT). Por su parte, Once al Sur se caracterizó por poner lo artístico al servicio del trabajo social, por trabajar en sectores marginados y por que su elección estética estaba marcada por las experiencias del Living Theatre ${ }^{5}$ Jerzy Grotowski ${ }^{6}$.

Un elemento que tenían en común estos colectivos era que utilizaban la metodología de la creación colectiva, la participación popular y la toma del espacio público. Para Verzero (291), la apropiación del espacio público es una forma de consolidar la idea de comunidad a partir de la expresión de cuestiones colectivas, al mismo momento que se produce una transformación en los límites entre lo público y lo privado, y que resalta la incidencia de la política en la vida cotidiana. Alverto Sava (37-9) coincide con Verzero y destaca que el

3 Silvina Díaz (1) define al teatro antropológico como un modelo teórico y práctico que propone una concepción distinta del hecho escénico, y que instaura una ruptura respecto de la visión tradicional. Generado a partir de los principios legados por Antonin Artaud y por Jerzy Grotowski, fue concebido por Eugenio Barba, quien fundó el Odin Teatret utilizando este modelo. Las primeras noticias sobre Barba y su teatro llegaron a Argentina en los setenta a través de publicaciones teatrales, a partir de la década del ochenta por medio de estudios e investigaciones, y luego de modo más efectivo mediante la transmisión directa de la experiencia gracias a las visitas que el grupo hizo al país en los noventa. La vigencia del modelo antropológico puede observarse en la producción de diversos teatristas desde mediados de la década del ochenta, tales como Guillermo Angelelli y El Primogénito (Argentina); el Grupo Teatro Libre (Argentina), de Omar Pacheco; José María López y Kumis Teatro (Argentina); el Teatro Acción, de Eduardo Gilio (Argentina); Cecilia Hopkins; Periplo Compañía Teatral (Argentina); El Baldío, de Antonio Célico (Argentina); Viajeros de la Velocidad, de Daniel Misses (Argentina); El Bardo, de Diego Starosta (Argentina); El Muererío Teatro; César Brie (Bolivia) y los grupos nucleados en la Red de Teatro El Séptimo (Argentina), entre otros.

4 Erwin Piscator, director teatral alemán que, junto con Berolt Brecht, trabajó un teatro con fuerte contenido sociopolítico (Teatro Político del Proletariado). Propuso nuevas visiones en relación con el trabajo escénico y actoral, y defendió el teatro político pedagógico.

5 El Living Theatre fue una compañía teatral estadounidense fundada en 1947 cuyos principios estuvieron ligados al teatro de Artaud y de los anarquistas de principios de siglo XX. Su propuesta consistía en vivir la vida cotidiana en comunidad, en generar espectáculos que incentivaran la participación del espectador, en utilizar espacios no convencionales y en la improvisación.

6 Jerzy Grotowski fue un director de teatro polaco que se basó en la idea de encontrar la pureza del hecho teatral despojándolo de todo lo que no sea el actor, para centrarse en él como pieza fundamental de la obra. Su propuesta acercaba el teatro a los conceptos de ritual, ceremonia y encuentro espiritual. Eugenio Barba y Peter Brook son reconocidos por haber rescatado su legado. 
movimiento teatral de los sesenta se caracterizó por invocar un cuestionamiento al espacio escénico tradicional, a la relación actor-espectador, al texto y las técnicas actorales. Schechner (231-50) completa el panorama de la década del sesenta afirmando que en ese momento histórico se trataba de mostrar al espectador el proceso de elaboración de la obra para generar su participación, en un intento de privilegiar la eficacia del teatro por sobre el entretenimiento.

Es importante tener en cuenta que el ambiente teatral de principios del siglo XX estaba impregnado por una crítica al orden político a través de la puesta en escena, que tenía su origen en las propuestas contestatarias al orden social de autores, algunos ya mencionados, como Vsévolod Meyerhold, Antonin Artaud, Erwin Piscator y Bertolt Brecht. Durante la segunda mitad del siglo XX, además de la forma y el contenido se empezaron a cuestionar desde el teatro las relaciones sociales, y muchos grupos de identidad étnica, trabajadores, vecinos y profesionales presentaron espectáculos en espacios públicos (Borba 2).

En los setenta ya nos encontramos con lo que Pianca reconoce como el momento de cuestionamiento y modificación del paradigma teatral, cuando la politización se extrapolaba a la vida cotidiana y los grupos teatrales buscaban "concientizar" al público transformando la percepción del espectador (Dacal 19). A principios de la década surgieron dos experiencias de teatro militante ligadas directamente al peronismo, que desarrollaron un trabajo artístico en zonas marginales simultáneamente a la actividad gremial, y algunas incorporaron la lucha armada. Se trataba del Centro de Cultura Nacional José Podestá y del Grupo Octubre, liderado por Norman Briski. El primero fue fundado en 1973 como órgano de agitación y propaganda peronista del Frente Justicialista de Liberación Nacional (Frejuli). Su trabajo se limitó solo a ese año, en el que utilizaron métodos de creación colectiva con textos previamente escritos por otros autores. El Grupo Octubre funcionó durante los años 1970 a 1974, y si bien estaba ligado al peronismo de base, sus propuestas estaban enfocadas en las problemáticas sociales en sentido amplio, con un fuerte componente territorial local.

Por último, las experiencias de mimo contemporáneo y teatro participativo, que se desarrollaron entre 1971 y 1974, se centraban en el rol social del arte y la utilización de espacios reales para la puesta en escena. Se buscaba incentivar, a través de la teatralización en espacios cotidianos, la participación del público para crear un sistema de comunicación abierto. La idea era promover al artista como agente de cambio, que rompe con la estructura teatral tradicional. Por ese motivo representaban obras en espacios no convencionales como ascensores, restaurantes, escuelas o cualquier lugar público (Sava 10-4).

Las experiencias que acabamos de recopilar denotan una tendencia a comprender al teatro en su función pedagógica. Los estudios de Paulo Freire sobre la pedagogía del oprimido ${ }^{7}$ sirvieron de base para la elaboración y sistematización de teorías y técnicas

7 La pedagogía del oprimido de Paulo Freire presenta un sistema de oprimidos y opresores, en que la opción pedagógica liberadora se encuentra en el diálogo entre el educador y el educando, de modo que ambos aprenden al mismo tiempo. Es en este proceso en el que se reflexiona sobre la propia condición y se devela la educación como práctica de la libertad. 
actorales. Las propuestas de Augusto Boal $^{8}$ también tuvieron un fuerte impacto en los colectivos artísticos argentinos de los sesenta y setenta. La ruptura que Boal produjo en el teatro estuvo ligada a la participación del espectador, al que convirtió en parte fundamental de la obra. Las temáticas de tono social desarrollaban la idea de la explotación y la opresión del hombre por parte del sistema político, y la necesidad de la transformación del ser humano y de su situación social a través del teatro. Boal se exilió en Argentina en el año 1971, luego de ser encarcelado y torturado en Brasil, desde donde produjo muchos de sus textos más comprometidos.

\section{Fines de los setenta y década del ochenta}

Para abordar el tercer periodo esbozado por Pianca, que comienza en el año 1974, la dictadura militar se impone como proceso ineludible de análisis. Sabemos que el régimen implantado en Argentina durante los años 1976-1983 dejó un saldo de ausencias y rupturas en el ambiente artístico argentino, puesto que muchos artistas fueron víctimas de una sangrienta persecución. Cada uno de los campos del arte respondió de distintas maneras a esta situación, y si bien muchos optaron por el exilio, diversas expresiones artísticas y teatrales funcionaron durante el periodo de forma clandestina e incluso sufrieron la censura y la represión (Dubatti, Teatro y producción de sentido político en la postdictadura 27).

Lvovich y Bisquert (30) identifican como uno de los principales objetivos de los militares la búsqueda del disciplinamiento social, en consonancia con lo que consideraban los valores de "un buen argentino". El mantenimiento de estos valores implicaba aniquilar a los sujetos que hacían un libre uso de sus relaciones sociales (Fierstein 15). De esta forma, al disciplinamiento de lo cotidiano se sumaron la limitación de las diferencias, la coacción de instituciones y la eliminación de una cultura política igualitaria (Alonso 58). Tal como afirma Marina Pianca (255), las dictaduras, en especial las castrenses, señalan a la actividad intelectual y cultural como las responsables de la agitación social, cuyo objetivo sería la transformación profunda de todas las estructuras de lo social. Es por eso que las expresiones teatrales que desafiaron los valores del "buen argentino" se convirtieron en una víctima más del sistema represivo; muchos de los grupos que habían surgido durante los sesenta y setenta en Argentina se disolvieron por motivos internos o se vieron obligados al exilio o la clandestinidad.

La experiencia de Teatro Abierto se considera la primera voz colectiva que, en Argentina, se alzó desde el arte en defensa de la libertad de expresión y los derechos humanos (Díaz, "El teatro como ámbito de resistencia: identidad, inmigración y exilio" 1).

8 Augusto Boal parte de la idea de que existen oprimidos/opresores y comienza a gestar la idea del teatro del oprimido en los años sesenta. Su objetivo era generar, por medio de la transformación del espectador en actor, un proceso a través del cual este fuera tomando conciencia de su situación y pudiera generar un cambio en sus condiciones reales de vida (liberarse). Estuvo fuertemente influenciado por la pedagogía del oprimido de Freire y por el teatro épico de Brecht. 
Este movimiento de protesta contra la dictadura nació gracias a la iniciativa de un grupo de actores, directores y dramaturgos profesionales. Las características de las obras representadas por este grupo se acercaban a lo que Pelletieri denominó realismo reflexivo, que retoma los géneros del grotesco, el sainete y el absurdo, los refuncionaliza, y por medio de la metaforización critica al contexto de forma oscura e indirecta. La idea era explorar los momentos dolorosos que estaba viviendo la sociedad argentina (Díaz, "El teatro como ámbito de resistencia: identidad, inmigración y exilio" 3). Los veintiún actores que participaban en Teatro Abierto provenían del sistema teatral de los sesenta, pertenecían a lo que había sido el Teatro Independiente, y entendían al arte como un compromiso y como una forma de conocimiento (Pelletieri, La puesta en escena argentina de los '80: Realismo, estilización y parodia 4). El 28 de julio de 1981 el teatro El Picadero, en donde este grupo ensayaba, fue quemado intencionalmente. A pesar de ello el proyecto siguió funcionando hasta 1986, aunque comenzó a perder fuerza a partir del retorno de la democracia en 1983. Pelletieri (La puesta en escena argentina de los '80: Realismo, estilización y parodia 6) afirma que la desaparición de este movimiento estuvo signada por la ausencia de aquello sobre lo cual se buscaba generar cuestionamientos: el sistema de gobierno represivo.

\section{Los dinosaurios van a desaparecer: vuelta a la democracia}

Cuando asumió Raúl Alfonsín como presidente, en diciembre de 1983, se abrió una nueva etapa en el país, que generó rupturas pero también mantuvo continuidades con el régimen anterior. En el ámbito teatral, en el momento de la transición democrática la formulación de políticas culturales estuvo fundada en la valorización de los derechos humanos (Wortman en Raimondi 3). Surgió así lo que Dubatti (Teatro y producción de sentido político en la postdictadura 9-10) denomina el canon de la multiplicidad, una diversidad de experiencias teatrales que se expresan desde un punto de vista microsocial, que son notablemente heterogéneas en sus formas, y muchas de las cuales utilizaron la calle como espacio privilegiado de representación. Para Pelletieri (La puesta en escena argentina de los '80: Realismo, estilización y parodia 7-13), en la segunda mitad de la década de 1980 se generó un nuevo sistema teatral del cual surgieron varias propuestas estéticas. Algunas de ellas retomaron las tradiciones de los años cincuenta o sesenta y las continuaron, mientras que otras las retomaron pero las refuncionalizaron a la luz de las nuevas coyunturas políticas y sociales, y otras se encargaron de parodiar las viejas formas de representación. Si bien todas ellas respondían a un patrón de ruptura con los modelos sesentistas, los modelos teatrales eran diferentes en cuanto a contenido, puesta en escena, relación con el público y objetivos; como se explicó, diferían principalmente en el modo de pensar la ruptura con el teatro de los sesenta.

Nos vamos a centrar en el último tipo de teatro, llamado de parodia. Esta forma se apropia del modelo sesentista pero lo corrompe y lo transforma en algo diferente, ya que sus propósitos estético-ideológicos son opuestos. Son puestas de resistencia, cuestio- 
nadoras del teatro serio, por lo que utilizan la transgresión, la inversión y la exposición de textos parodiados (Pelletieri, La puesta en escena argentina de los '80: Realismo, estilización y parodia 13-4). Para Beatriz Trastoy (6-7), la estética de los ochenta propone la jerarquización del gesto por sobre la palabra, la integración de los lenguajes corporales de otras áreas a los sistemas teatrales, y una impronta transgresora de la estética que incluye un híbrido de varieté, music hall, revista, circo y murgas. Es un teatro de intertexto que retoma estos elementos para la escena e incorpora la creación del espacio en lugares no convencionales. Esta forma de hacer teatro fue la elegida por muchos grupos de teatro callejero, antecedente fundamental del teatro comunitario.

\section{La calle}

André Carreira define al teatro callejero como "un espectáculo que se realiza al aire libre, en espacios no convencionales, generando una doble transgresión, del canon teatral como de la codificación estandarizada de los espacios del cotidiano" (cit. en Heram 10). Héctor Alvarellos lo define como "el que físicamente está más cerca del pueblo" (11). Para Patrice Pavis es "el teatro que se produce fuera de los edificios teatrales convencionales: la calle, la plaza, el mercado, el metro, la universidad” (477).

Más allá de las múltiples acepciones de la categoría ${ }^{9}$, lo cierto es que al comienzo de la década del ochenta y como resultado del proceso de apertura política que se generó con el retorno de la democracia, el teatro salió a la calle a través de numerosas agrupaciones que tenían como lema transformar al teatro desafiando los espacios de representación tradicionales y resaltando su función social. La definición más acabada, que describe al teatro callejero a partir de su momento histórico concreto, es la propuesta por Dacal (13), quien es considerado el fundador de Teatro de la Libertad, uno de los grupos de teatro callejero nucleados en el Movimiento de Teatro Popular (Motepo) ${ }^{10}$, conformado en 1987. Dentro de este movimiento se encontraban el Grupo de Teatro Catalinas Sur -considerado fundador del teatro comunitario- y los Teatreros Ambulantes Los Calandracas, el segundo grupo de teatro comunitario en orden de aparición.

Dacal (13-6) no solo ubica al teatro callejero en un espacio físico -fuera de los recintos cerrados-, sino que también plantea transformaciones en el público y en el actor, y además identifica una metodología de trabajo particular. La experiencia se convierte en pedagógica no solo para el público (que se transforma de transeúnte en espectador,

9 Para Jorge Dubatti es una práctica ancestral que logra captar al público involuntario, para Roberto Uriona, de Diablomundo, hay diferencias entre el teatro de calle y el teatro callejero, mientras que para el Grupo Dorrego es la expresión más sincera del artista.

10 Los grupos que conformaban el Motepo eran la Agrupación Humorística La Tristeza, la compañía teatral el Arco Iris Enojado, el Centro de Investigaciones Titiriteras, Diablomundo, la Cooperativa Teatral Rayuela, el Grupo de Teatro Catalinas Sur, el Grupo de Teatro Encuentro, el Grupo La Obra, el Grupo Otra Historia, el Grupo Teatral Dorrego, el Teatro de la Libertad y los Teatreros Ambulantes Los Calandracas. 
con lo cual se logra complicidad inmediata), sino también para los teatristas, que toman conciencia de la acción que representa llevar el teatro al espacio público, quitándole su condición de ritual sacralizado. Se toma contacto con la memoria colectiva y la realidad sociopolítica de la comunidad, porque se extraen los contenidos de las obras de mitos, historias y leyendas de la memoria popular.

A diferencia de Dacal, para quien el teatro callejero es de por sí un teatro popular, Alvarellos (23) afirma que el teatro popular es independiente del lenguaje teatral que utilice, ya que puede o no ser popular, es decir, portador de un lenguaje "accesible" para todos. Cuando se disolvió el Motepo, en 1991, se formó Entepola ${ }^{11}$ (Encuentro de Teatro Popular Latinoamericano). Para Alvarellos, muchos de los grupos miembros de esta última agrupación se alejaban de las formas fácilmente decodificables, a raíz de la búsqueda de nuevos lenguajes estéticos.

En el próximo apartado reconstruiremos el momento en el cual tuvo lugar el surgimiento del grupo Catalinas Sur, al que los investigadores de teatro comunitario han identificado como el grupo fundador en Argentina (Bidegain, Teatro comunitario. resistencia y transformación social 26; Proaño Gómez, El desplazamiento de la política 1; Scher 133). Luego, encaminaremos la discusión hacia las particularidades de este teatro y estableceremos el diálogo con experiencias teatrales previas, para de este modo reconstruirlo como una nueva forma de teatro con características específicas.

\section{Esperando nacer}

Este apartado se divide en dos secciones con el fin de ordenar, por un lado, la reconstrucción histórica del surgimiento del teatro comunitario y su desarrollo, y, por el otro, la discusión teórica en torno a su definición como forma de teatro. Si bien ambas secciones dialogan, esta división puede aportar claridad a la exposición.

\section{Desde el espíritu de El Picadero}

\section{1.a. Los iniciadores}

En 1982, bajo el mandato de Osvaldo Cacciatore como gobernador de la ciudad de Buenos Aires, un grupo de padres nucleados en la Asociación Mutual de la Escuela No 8 Carlos Della Pena, del barrio porteño de La Boca, realizaba trabajos a nivel barrial. Hacia finales de ese año, luego de ser expulsados de la mutual de la escuela por las fuerzas del gobierno de facto, alquilaron un local y posteriormente se mudaron a uno prestado donde dieron

11 Hoy el Entepola sigue funcionando, pero se define como Festival Internacional Teatro Comunitario. 
varios talleres, entre ellos uno de teatro que duró tres meses. Cuando en marzo de 1983 la profesora de teatro planteó que no podía ir más a dar el curso, Mónica Lacoste ${ }^{12}$ propuso convocar a un director uruguayo que se había radicado en Argentina, a quien le interesaba el teatro en la plaza (Bidegain, Marianetti, Quain y Cabanchik 15). El director uruguayo era Adhemar Bianchi.

Bianchi tenía una vasta trayectoria en el mundo del teatro ligada a la militancia política, ya que en Uruguay había participado del teatro de agitación ${ }^{13}$ en barrios y fábricas y en los Grupos Sesenta y Cinco y el Teatro Circular. Pero fue a principios de los ochenta cuando realizó por primera vez un trabajo con un grupo grande de vecinos en la Asociación de Bancarios del Uruguay, y decidió comenzar a explorar el campo teatral con personas no profesionales del teatro (Scher 136). Cuando el grupo de padres de la escuela Della Pena le propuso a Bianchi dar los talleres, comenzaron a hacer teatro en la plaza Malvinas y luego alquilaron un local en la calle Olavarría, que utilizaban para guardar sus cosas o para ensayar en días de lluvia. El grupo de teatro recién formado, que adoptó el nombre de Grupo de Teatro al Aire Libre Catalinas Sur, comenzó a trabajar con vecinos a través de la creación colectiva.

Luego de diez años de intensa actividad y ya reconocido con el nombre de Catalinas Sur, el grupo firmó un convenio con la Dirección de Promoción Cultural de la Secretaría de Cultura de la Ciudad de Buenos Aires, del cual consiguieron el apoyo del Programa Cultural en Barrios. Se empezaron a dar talleres de teatro, percusión, música, títeres, máscaras, escenografía, vestuario, malabares, zancos, coros, candombe, murga, entre otros. En 1997 se trasladaron a un galpón techado ubicado en el centro del barrio de La Boca, que compraron en 1999 (Bidegain 69). Su trayectoria como compañía internacional de teatro destaca por su calidad estética, las estrategias para conseguir recursos y la relación que establecieron con la comunidad. En sus treinta años de trayectoria han recibido innumerables premios nacionales e internacionales. Cuentan con el apoyo de fundaciones, organismos nacionales e internacionales y tienen más de quince espectáculos estrenados.

Como ya señalamos, hacia 1987 se conformó el Motepo, agrupación de la cual Catalinas formó parte. Fue allí donde tomó contacto con el grupo Los Calandracas, del barrio de Barracas, y comenzaron a trabajar de forma conjunta. Los Calandracas, que hizo su primera presentación en 1988, estaba conformado por cinco teatristas que se habían conocido en 1985 en un seminario de perfeccionamiento actoral en Avellaneda (Bidegain 110). A partir del Congreso Argentino de Pediatría que se realizó en Buenos Aires (1988) y al que Los Calandracas fueron convocados para participar desde un enfoque distinto sobre la Atención Primaria de la Salud, el grupo formuló ciertos principios que

12 Integrante pionera del grupo Catalinas Sur. Años más tarde fundó un grupo de teatro comunitario en Málaga, España.

13 Patrice Pavis (472) define al teatro de agitación como una forma de animación teatral cuyo propósito es sensibilizar al público con respecto a una situación política o social. 
guiarían su labor teatral. Se lo denominó teatro para armar y se concentró en temas como la atención a la mujer embarazada, los adultos mayores, la prevención de las adicciones, la violencia y la comunicación en la escuela. El vínculo de Ricardo Talento, su director, con el teatro de vecinos tiene origen en las primeras experiencias de su adolescencia e infancia y en las iniciativas de su padre, cercano al mundo circense. Talento formó parte desde 1972 del Grupo Cumpa ${ }^{14}$, que se desarmó en 1976. Participó del seminario de perfeccionamiento actoral en Avellaneda y allí conoció a los que serían sus compañeros en Los Calandracas (Scher 156).

Si bien la trayectoria de Los Calandracas comienza con las experiencias de los ochenta, se consolidó como grupo en la década del noventa y en 1996 se estableció en su espacio propio del barrio de Barracas; el galpón se bautizó con el nombre de Circuito Cultural Barracas. Como resultado de los talleres que se dictaban en el Circuito, se creó la murga Los descontrolados de Barracas, y de los talleres de actuación surgieron el Teatral Barracas y Los payasos del Circuito.

En 1996 la agrupación de titiriteros Kossa Nostra, de la ciudad de Posadas (provincia de Misiones), tomó contacto con el grupo Catalinas Sur y gestionó la presentación de uno de los espectáculos tradicionales de Catalinas, Venimos de muy lejos, en la tierra misionera. En 1999, a través del proyecto "Misiones, tierra prometida", se conformó en Posadas el grupo autodenominado de teatro-fiesta La murga de la Estación. En el año 2000 este grupo se organizó en la asociación civil sin fines de lucro Grupo de la Estación, que nuclea actualmente a un centenar de personas de diferentes edades y trayectorias sociales. Por iniciativa de este grupo, empezaron a dictarse talleres y a convocarse a los habitantes de localidades aledañas, como la ciudad de Oberá. Fue así que vecinos de esta región participaron de las reuniones que comenzaron en el año 2000 en un galpón ofrecido por la municipalidad local, y para junio de ese año ya estaba conformada La murga del monte, de Oberá. Estos grupos también cuentan con el apoyo de organismos nacionales y municipales que avalan las actividades y auspician los eventos.

\section{1.b. Crisis y multiplicación de grupos}

El año 2001 se convirtió en un momento bisagra que dio origen a la "explosión del teatro comunitario" (Proaño Gómez, "El desplazamiento de la política: teatro comunitario argentino" 159; Bidegain 22; Rosemberg 15). En los dieciocho años que transcurrieron entre la creación de Catalinas y el año 2001, podemos reconocer la existencia de cuatro grupos (Catalinas, Barracas, Murga del monte y Murga de la Estación); pero a partir de 2002 hasta hoy, los grupos han proliferado y ya suman más de cincuenta en toda la Argen-

14 El Grupo Cumpa estaba formado por Armando Corti, Mauricio Kartun, Mónica Estevez, Marta Larreina, Carlos Rodríguez Méndez y Alberto Silva. Montaron la obra ¿Civilización o barbarie?, de Humberto Rivas y Mauricio Kartun, con la que salieron de gira hasta 1975. 
tina. A partir de la crisis conocida como la crisis del 2001, el estallido o El Argentinazo, se produjeron modificaciones políticas, sociales y culturales que permitieron la emergencia de nuevos sujetos sociales y nuevos espacios de construcción política.

Analizaremos en qué medida este proceso de apertura política, que surgió debido a la crisis, atravesó la práctica del teatro comunitario y sus modos de funcionamiento. Por otra parte, abordaremos el análisis de la relación entre los sucesos que marcaron este momento histórico y la proliferación de los grupos de teatro comunitario.

En la década del noventa, durante el gobierno de Carlos Menem, la consolidación del modelo económico neoliberal -que tomó forma a través de la Ley de Convertibilidad, las privatizaciones y la apertura económica- derivó en el aumento de la pobreza y en una fuerte concentración económica en el sector financiero. El objetivo de la Ley Nacional del Empleo (1991) fue luego continuado por las políticas del gobierno de La Alianza ${ }^{15}$, lo que profundizó el quiebre del poder sindical, el empobrecimiento y la segregación socioespacial de los sectores populares. El intento del gobierno radical por mantener la Ley de Convertibilidad condujo a un endeudamiento externo cada vez mayor y a fines de noviembre de 2001 comenzó la fuga de capitales de los inversores extranjeros. A principios de ese mes se dio a conocer públicamente la nueva medida económica que restringió el retiro de los depósitos bancarios, más conocida como el corralito financiero. La crisis culminó con acciones de protesta masivas (cacerolazos) y con la renuncia del presidente radical Fernando de la Rúa, el 20 de diciembre de 2001. El estallido resultó en la muerte de casi cuarenta personas y en la acefalia presidencial. Fue un momento histórico que dio cuenta de procesos políticos que estaban germinando desde hacía varios años en el país. El nuevo escenario otorgaba mayor visibilidad a los movimientos sociales, como, por ejemplo, a las organizaciones piqueteras.

Svampa (205-60) identifica un periodo claramente marcado por la conflictividad social, que hacia finales de 2001 tornó visibles a muchos grupos que estaban desarrollando experiencias colectivas de información alternativa o proyectos culturales en vinculación con otras organizaciones sociales ${ }^{16}$. Para la autora, lo propio de estos grupos sería la afirmación de la subjetividad a través de la acción directa y el rechazo a la creciente mercantilización de la vida social, como también la articulación que generaron con otras organizaciones a nivel nacional e internacional.

Dentro de este contexto de movilización política que describe Svampa, la organización de gran parte de los vecinos a través de las asambleas barriales fue considerada el embrión de muchas formas organizativas posteriores, entre ellas la conformación de grupos de teatro comunitario. Sin embargo, coincidimos con Scher (65-75), quien considera una deducción mecanicista suponer que el teatro comunitario es una consecuencia directa del movimiento asambleario.

15 La Alianza por el Trabajo, la Justicia y la Educación fue una alianza política entre la Unión Cívica Radical y el Frepaso (1997), que se disolvió luego de la renuncia del presidente De La Rúa el 20 de diciembre de 2001.

16 Dentro de estos colectivos la autora identifica al Taller de Serigrafía Urbana o Arte Arde. 
En efecto, si trazamos la línea de trayectoria de los grupos que iniciaron sus actividades en los años inmediatamente posteriores a 2001 (2002 y 2003), de los testimonios de los iniciadores se desprende que la experiencia de las asambleas barriales no es un factor común como antecedente organizativo. Solo dos de los grupos -Almamate, de Flores, y Villurqueros, de Villa Urquiza- reconocen que las asambleas barriales de 2001 tuvieron algún grado de incidencia en la conformación del grupo. En el caso de Almamate, en la Plaza de los Periodistas (su habitual lugar de ensayo en el barrio porteño de Flores) había una murga llamada Arrebatalágrimas, que venía trabajando desde antes de 2001 en aquel lugar público, en donde los vecinos también habían organizado una asamblea barrial y una feria para los fines de semana. Una de las mujeres que formaba parte de esta murga leyó una nota en el diario Página 12 sobre el trabajo que estaban realizando Talento y Bianchi en el teatro comunitario y pensó en participar. Se comunicó con Talento, quien la incentivó a crear un nuevo grupo en Flores.

En el caso de Villurqueros, tanto la futura directora del grupo (Liliana) como su esposo pertenecían al ámbito del teatro y participaban de una asamblea barrial. La idea de Liliana era armar un grupo de teatro comunitario que formara parte del área de cultura de la asamblea, pero no hubo consensos en cuanto a quién debía dirigir el grupo. Esta área comenzó a trabajar sola en la idea del grupo de teatro, que pasó a ser una convocatoria concreta con la llegada de Mariela Pacheco, una teatrista que había pertenecido al Motepo.

En 2002, Catalinas Sur y el Circuito Cultural Barras gestionaron un proyecto con el Gobierno de la Ciudad de Buenos Aires. Se trató de una Carpa Cultural Itinerante que llevaba la función de Catalinas Sur, Venimos de muy lejos, a diferentes barrios de la ciudad con el fin de generar nuevos grupos. Luego, la función se complementaba con una charla a los vecinos guiada por Talento y Bianchi. La iniciativa también era difunfida por diferentes centros culturales del Programa Cultural en Barrios. De este proyecto itinerante surgieron tres grupos ${ }^{17}$.

Muchos de los fundadores de estos grupos estaban ligados a alguna institución gubernamental o no gubernamental, por medio de la cual tomaron contacto con las actividades que estaban llevando adelante Bianchi y Talento. Eran personas que habían pertenecido al campo teatral ya sea a través del trabajo barrial, de tareas docentes en centros culturales, en grupos de teatro independiente o que dirigían sus propios grupos teatrales. También resultó fundamental el contacto que tomaron estos directores con las funciones de Catalinas Sur y Barracas, experiencias que muchos de ellos recuerdan como el puntapié inicial que despertó su interés en el teatro comunitario. Si revisamos las trayectorias de estos directores, se distinguen experiencias teatrales previas como el movimiento de teatro independiente, el Motepo y la antropología teatral de Eugenio Barba.

Si bien la crisis del año 2001 generó nuevos espacios de construcción política, las aberturas por las cuales el teatro comunitario fue tomando lugar en la escena cultural se

17 Res o no Res (Mataderos), Los Pompapetriyasos (Parque Patricios) y como desprendimiento de este último, el Grupo de Teatro Comunitario de Pompeya. 
generaron en diversos frentes. Por un lado, el contexto de movilización social y política permitió que muchos colectivos artísticos se visibilizaran, y otros se conformaran a la luz de la nueva coyuntura, irrumpiendo en los espacios públicos para reclamar por nuevas demandas. En este marco, los nuevos proyectos artísticos conformados fuera del circuito comercial adquirieron más notoriedad. Por otra parte, el apoyo institucional y material que brindó el entonces Gobierno de la Ciudad de Buenos Aires a través de proyectos como la Carpa Cultural Itinerante y el Programa Cultural en Barrios, junto con la iniciativa constante de Talento y Bianchi por transmitir la experiencia, se convirtieron en la conjugación perfecta para que se difundiera la actividad en toda la ciudad. Tampoco se pueden dejar de mencionar las múltiples actividades que Bianchi y Talento desarrollaron por fuera de la ciudad porteña (seminarios, charlas y funciones), que colaboraron con la conformación de nuevos grupos en toda la provincia y generaron la demanda de nuevas capacitaciones en pueblos del interior e incluso en otras provincias.

Por su parte, entidades nacionales como el Instituto Nacional del Teatro, provinciales como el Instituto Cultural de la Provincia de Buenos Aires y la Comisión Provincial por la Memoria (con sede en La Plata), participaron en la gestión de subsidios y proyectos que impulsaron notablemente la actividad del teatro comunitario por fuera de la ciudad de Buenos Aires. El Proyecto Escenarios ${ }^{18}$, a través del cual surgieron el Grupo de Teatro Comunitario de Berisso y Los Tololosanos (grupo de Tolosa), brindó los recursos para que algunos directores teatrales que ya estaban interesados en trabajar con los vecinos de un barrio tuvieran el espacio y los recursos para hacerlo.

Cuando la cantidad de grupos comenzó a aumentar, decidieron organizarse en torno a una Red Nacional (cfr. Red deTeatro Comunitario), de la cual se desprendería luego la Red Regional Sur, que reúne a grupos de La Plata y algunos de la provincia de Buenos Aires. Los mismos integrantes se encargaron de transmitir la experiencia a otros lugares, con lo cual empezó a generarse una demanda de seminarios y talleres. Talento y Bianchi comenzaron a capacitar y apoyar a grupos en formación o directores que querían construir un grupo en su lugar de origen.

\section{Hacia la construcción de una nueva forma-teatro}

Los pocos estudios que abordan el tema del teatro comunitario lo conceptualizan como un teatro de vecinos para vecinos. Esta primera acepción fue formulada por Bidegain (11) en el primer escrito argentino que sistematizó esta experiencia, titulado Teatro comunitario, resistencia y transformación social. En los trabajos posteriores los autores retomaron esta conceptualización y fueron desarrollando aspectos particulares de la práctica comunitaria.

18 El Proyecto Escenarios - promovido por el Instituto Cultural de la Provincia de Buenos Aires- se enmarcaba dentro de la categoría "proyectos temporales", y tuvo el fin de generar polos culturales con la modalidad de teatro comunitario en Berisso, Tolosa y Ensenada. 


\section{2.a. Desafíos conceptuales}

Conceptualizar la práctica del teatro comunitario es un desafío porque se trata de una expresión artística en constante construcción. En esa mutación los conceptos adquieren diversas significaciones y quedan caducos con el transcurso de la historicidad. Los trabajos académicos sobre el tema han tomado un gran impulso gracias a un conjunto de jóvenes investigadores que encontraron en él un objeto de análisis. La Red de Investigadores de Teatro Comunitario ${ }^{19}$ los nuclea con el fin de que el conocimiento pueda ser utilizado por los grupos para reflexionar sobre su práctica.

El primer desafío para pensar al teatro comunitario es la heterogeneidad de las propuestas que lo componen, producto del componente territorial que lo define. En trabajos anteriores (Fernández, Grupo de Teatro Popular de Sansinena. Nuevos abordajes para su análisis 8) hemos señalado la dificultad de construir una categoría acabada que permita dar cuenta de la forma teatro comunitario y que no resulte limitante para pensarlo en su complejidad. Las condiciones objetivas que se le otorgan a un territorio y determinados rasgos identitarios (cantidad de habitantes, condición social, acceso a bienes materiales y simbólicos, infraestructura, prácticas, historia), generan relaciones sociales específicas de ese lugar. Es decir, una práctica artística se puede conceptualizar por medio de los elementos que la componen y le dan forma, pero esa conceptualización se verá flexibilizada, transformada, de acuerdo con las lógicas propias del territorio en el cual se desarrolle, el cual también se modificará a raíz de la práctica artística. Esta dinámica de doble transformación, en la cual no puede pensarse una sin la otra, da cuenta de las dificultades con las que nos encontramos al intentar unificar metodologías, estrategias y lógicas universales a todos los grupos. Otras cuestiones como la trayectoria, la antigüedad, la experiencia, y el manejo de capitales simbólicos y materiales, producen abismales diferencias entre los grupos de la Red.

\section{2.b. Acuerdos y desacuerdos: no todo es lo mismo}

El teatro comunitario se ha definido como un teatro de vecinos para vecinos, porque es practicado específicamente por los vecinos de un territorio determinado, que puede ser un barrio pequeño, una localidad, un pueblo o una ciudad. Yamila Heram (3) coincide con Edith Scher (63), Ángela Greco (6-8) y Marcela Bidegain (36) al señalar la no profesionalidad de los integrantes de los grupos de teatro comunitario como la particularidad que lo diferencia del teatro popular o callejero de los años ochenta.

19 La Red de Investigadores de Teatro Comunitario funciona en el Centro Cultural de la Cooperación Floreal Gorini, en Capital Federal, y cuenta con investigadores de diversas provincias de Argentina, Brasil, Suiza y Francia (http:// investigadoresdetc.blogspot.com.ar/). 
La alusión a la comunidad está muy presente en las definiciones que hacen estas autoras. Para Proaño Gómez (Poéticas de la globalización en el teatro latinoamericano 8), los grupos de teatro comunitario parecen haber logrado concretar la idea de comunidad. Pero no una comunidad en donde se homogenizan las diferencias, sino una basada en la relación ética/estética/vivencial con el otro, en la que se funda un "nosotros" al que se aduce pertenencia y en donde se aprovechan esas diferencias. Por su parte, Bidegain, Marianetti, Quain y Cabanchik (30-3) refieren a una comunidad no cerrada, donde se torna imprescindible la "obligación fraternal" de compartir los beneficios entre sus miembros.

En esta noción de comunidad adquiere relevancia una característica distintiva del teatro comunitario en relación con otros grupos teatrales: el acceso a los grupos no tiene restricciones, lo que significa que cualquier persona que esté interesada puede participar. La edad, el sexo, la situación social o cualquier otra condición no podrán convertirse en un obstáculo para acceder al grupo. El hecho de que la lógica del teatro comunitario no marque diferencias en cuanto a las filiaciones partidarias o religiosas permite que no se cancele el reconocimiento identitario diferencial de sus integrantes. Scher (87) destaca la riqueza que aportan los intercambios generacionales, la que se ve potenciada por tratarse, en la mayoría de los casos, de grupos numerosos.

\section{2.c. Gestión}

Desde un comienzo la experiencia fue definida como autogestiva (Proaño Gómez, El desplazamiento de la política: teatro comunitario argentino 8; Bidegain 53; Greco 22-3). Si bien los grupos no fueron el resultado de una inversión financiera o un proyecto artístico comercial, con el paso del tiempo se necesitaron recursos para acceder a los elementos necesarios para la actividad teatral como el vestuario, el maquillaje, la utilería, etcétera. En ese tránsito de la autogestión por medio del paso de la gorra hacia otros mecanismos más complejos de financiamiento, algunos grupos conformaron una asociación civil, figura legal que les permitió acceder a subsidios o ayudas de diversas instituciones, mientras que otros optaron por contribuir con el grupo todos los meses, aportando una pequeña cuota societaria para gastos generales, y otros grupos construyeron estrategias de articulación con instituciones para generar intercambios de recursos.

Edith Scher (121) -directora del grupo de teatro comunitario Matemurga (Villa Crespo) e investigadora- refiere que la "gestión" es un tema tabú para el teatro comunitario. La autora intenta establecer ciertas etapas por las cuales los grupos de teatro comunitario van atravesando, de manera que a medida que el grupo va creciendo en cantidad, producción y reconocimiento, la gestión de recursos representa un desafío cada vez mayor.

Muchas de las problemáticas generadas por la gestión de recursos tienen que ver con los criterios adoptados para la selección de quiénes serán los que otorguen el beneficio (un subsidio, una ayuda económica, etcétera) y quiénes serán los destinatarios del mismo. 
Cada grupo escoge una estrategia, la que estará ligada a su capacidad de gestión, recursos humanos y vínculos con otras instituciones.

Desde la mirada de Greco (23), la estructura organizativa autónoma con la que nacieron los grupos de teatro comunitario dificultó el desarrollo de actividades de autofinanciamiento, y por eso se necesitó una transformación funcional de la organización, como en el caso de Catalinas Sur. Este grupo se ha convertido en una compañía teatral de extraordinarias dimensiones (cuatrocientas personas), lo que desafía las características otorgadas en un primer momento al teatro comunitario. Greco propone que esta transformación funcional de la organización fue fundamental para generar un mecanismo de autofinanciamiento.

Pero la afirmación de Greco es materia de debate, puesto que algunos grupos han optado por modos alternativos de autofinanciamiento, más cercanos a la construcción de cooperativas de trabajo y microemprendimientos. Tal es el caso del grupo Patricios Unidos de Pie (del pueblo de Patricios, partido de Nueve de Julio) o de la Cooperativa La Comunitaria, del partido de Rivadavia (provincia de Buenos Aires). Estos grupos llevaron adelante otras estrategias de gestión y proyectos laborales y culturales a través de los cuales financiarse, lo que demuestra que la profesionalización de los grupos de teatro comunitario aborda una multiplicidad de factores que incluyen expectativas de grupo, trayectorias personales y colectivas, un imaginario futuro y la construcción de un proyecto político.

El Estado siempre ha estado presente en la dinámica de la obtención de recursos. En los inicios de la actividad del teatro comunitario, lo hizo propiciando la actividad a través de la Carpa Cultural Itinerante (Gobierno de la Ciudad, 2002), el Programa Cultural en Barrios (Gobierno de la Ciudad, desde 2002) y el Proyecto Escenarios (Instituto Cultural de la Provincia, Instituto Nacional del Teatro). Desde su creación en el año 2010, el Consejo Provincial de Teatro Independiente de la Provincia de Buenos Aires ha otorgado una serie de subsidios con los cuales muchos de los grupos de teatro comunitario se vieron beneficiados, $y$ el Instituto Nacional de Teatro financió la publicación de material bibliográfico sobre el tema.

\section{2.d. Temática de las obras}

Las obras teatrales representan temáticas relacionadas con el territorio en el cual el grupo nace; puede ser la reconstrucción histórica de un hecho particular (una huelga obrera, el cierre de los ramales del tren, la basura en las calles, la falta de rutas, etcétera), un problema actual que esté perjudicando al barrio en su infraestructura (por ejemplo, inundaciones o edificios rotos), situaciones que generan nuevos sentidos en cuanto al espacio (delimitación de barrios, ocupación de la plaza), la presentación de un futuro ficticio, disputas tradicionales entre instituciones (clubes de fútbol), demandas sociales concretas (falta de alimento, educación) o denuncias específicas (maltrato de la policía, falta de oportunidades para los jóvenes). Otros grupos retoman a clásicos como Shakespeare y hacen nuevas versiones de sus obras adaptando el lenguaje a la jerga local. 


\section{2.e. Metodología de trabajo}

La metodología de trabajo que utilizan los grupos de teatro comunitario comparte gran cantidad de elementos con el método de creación colectiva, creado por el colombiano Enrique Buenaventura ${ }^{20}$. Fundamentalmente, este método consiste en cuestionar la autoridad del director como la única figura capaz de organizar y proponer el trabajo del grupo. Se desafía la participación jerárquica de uno de los miembros del grupo por sobre los otros. Beatriz Rizk señala que el objetivo de Buenaventura radicaba en que la gente tomara conciencia de la inequidad y desigualdad del mundo social e incitarla a generar cambios. La misma autora destaca los estudios de Carlos José Reyes, quien denomina a la primera parte del trabajo de Buenaventura como "dialéctico-nacionalista" (Rizk 117), influida por el materialismo dialéctico histórico.

La creación colectiva surgió debido a la necesidad de encontrar temas entre los dramas cotidianos e históricos que determinan la nacionalidad, y de encontrar soluciones para los problemas de montaje que se originaban por el hecho de presentarse a un nuevo público proveniente del proletariado y de las capas medias del país (Daconte 92). La participación del espectador es fundamental, ya que se ve involucrado en una situación con la que se identifica y respecto de la cual le es difícil permanecer indiferente. Santiago García ${ }^{21}$, director de teatro colombiano y contemporáneo de Buenaventura, es considerado otro de los pioneros en la utilización del método de creación colectiva en el trabajo que viene desarrollando desde la década del sesenta en el teatro La Candelaria de Bogotá, Colombia. La construcción en conjunto, a la que todos aportan sus conocimientos y experiencias en el armado de la obra, es el elemento fundamental que el teatro comunitario tomó de la creación colectiva.

En el caso de los grupos de teatro comunitario, el proceso consiste en la construcción de un relato que se va armando a través del aporte de todos los integrantes del grupo, quienes ponen en común anécdotas, experiencias, documentos, lecturas o cualquier otro material. Luego de la puesta en común se realizan improvisaciones con una consigna particular: de allí surge la materia prima para las escenas de la obra. Este proceso es registrado generalmente por el director o coordinador, quien le dará forma de guion a esos registros. La figura del director la encarna la persona que cuenta con conocimientos profesionales y técnicos de la actividad teatral, quien se encarga también de ir perfeccionando las técnicas actorales y escénicas. En esta dinámica, muchas veces los vecinos e incluso los directores ponen en cuestión los roles. De modo recurrente se cuestiona el papel del director, ya sea porque los vecinos no se sienten lo suficientemente representados como para delegar

20 Buenaventura (1923-2003). Poeta, narrador, dramaturgo, director, profesor, teórico y pintor, creó en los años cincuenta el método de creación colectiva. Estuvo en Buenos Aires participando del grupo Fray Mocho, pero fue en el Teatro Escuela de Cali (TEC) donde desarrolló su método basado en dos líneas alternativas: por un lado, la búsqueda de la identidad nacional, y por el otro, la experimentación con los clásicos para buscar la particularidad a través de dramas universales (Rizk 118).

21 Actor de cine y teatro, dramaturgo, director de teatro y pintor nacido en Bogotá en 1928. También desarrolló el método de creación colectiva en el teatro La Candelaria, de Colombia. 
decisiones estéticas en las manos de esa persona, o porque denuncian verticalismo en el manejo de las consignas. Lo cierto es que los límites y alcances de la coordinación nunca dejaron de ser objeto de debate tanto en el interior como entre los grupos.

Estudiosos del teatro comunitario como Bidegain, Marianetti, Quain y Cabanchik (103), Proaño Gómez (Poéticas de la globalización en el teatro latinoamericano 165) y Scher (103) afirman que es un teatro que trabaja con la memoria colectiva de la comunidad. Retomando el sentido que Maurice Halbwachs (4) le da a la memoria colectiva, si bien el recuerdo siempre es individual, la memoria tiene un encuadre social, pertenece a un espacio tiempo determinado que le confiere ciertos rasgos específicos. Los mecanismos que activa el teatro comunitario en relación con la memoria son múltiples, complejos y contradictorios. Son reflejo del heterogéneo entramado que le da forma a los procesos de memoria, que incluye negociaciones, tensiones y experiencias vividas que constituyen a su vez un mapa identitario de esa comunidad. La transmisión de conocimiento es permanente en el cotidiano de las relaciones sociales y las prácticas culturales, pero las prácticas que componen al quehacer propio de este teatro interpelan en todas sus fases el ejercicio continuo de repensar la historia. Desde la puesta en común de experiencias para armar la historia, hasta las improvisaciones y los ensayos, estas acciones portan un grado de reflexión y debate colectivo que tiene a la transmisión como principal protagonista (Fernández, La transmisión de la memoria en el teatro comunitario argentino 3). Es tan relevante el papel que adquiere el testimonio oral, que Proaño Gómez ha designado a la poética del teatro comunitario como una poética del testimonio.

El proceso de identificación que se da entre los vecinos está vinculado con el reconocimiento de cierta interpelación que se lleva a cabo en el nivel de la adhesión, y que implica la incorporación de prácticas, valores e ideas a la vida cotidiana. El teatro comunitario opera con mecanismos que interpelan cuestiones identitarias, porque promueve la pregunta por el quiénes somos en oposición a otro, porque construye una imagen de qué queremos ser en el futuro y cómo fuimos en el pasado. Se ponen en juego sentidos de pertenencia, trayectorias, historias de vida, proyectos en común e imaginarios colectivos.

\section{2.f. Funcionamiento interno y distribución de tareas}

El modus operandi de los grupos de teatro comunitario es la división de tareas por medio de la implementación de áreas como maquillaje, vestuario, prensa, asociación civil (si la hubiere), música, entre otras. El trabajo en estas comisiones es voluntario porque no hay designaciones arbitrarias, y el modo organizativo hacia adentro de los grupos es horizontal, de modo que todo se debate durante asambleas (Bidegain 44-8). Muchos grupos articulan su trabajo con otras instituciones como fábricas, centros culturales, radios barriales o escuelas; sin embargo, el vínculo que cada grupo construye con la comunidad es distinto en cada caso, porque no siempre la labor teatral va acompañada de un anclaje territorial en el barrio. 
Si bien este modo organizativo es el que se ha transmitido en las primeras experiencias de Talento y Bianchi, no puede afirmarse que todos los grupos adquirieron esta dinámica y trabajen hoy en día con ella de forma regular. Las relaciones que se establecen entre los vecinos de un grupo y con las instituciones del barrio, alcanzan rasgos distintivos en función de los mecanismos que ese grupo desarrolle y las características territoriales y sociales de ese colectivo.

\section{2.g. Rasgos de la estética comunitaria}

\section{2.g.1. Sainete, grotesco y comedia del arte: nutrientes vitales del teatro comunitario}

En la estética del teatro comunitario conviven elementos del grotesco, el sainete y la comedia del arte. Conocer los elementos que componen estas expresiones y los momentos históricos en los cuales surgieron, contribuye a comprender la reapropiación de estos géneros en la contemporaneidad a partir de su incorporación en la estética teatral comunitaria.

Tanto Carella (5) como Pelletieri (El sainete y el grotesco criollo: del autor al actor 12) afirman que el sainete tiene un origen incierto, pero ubican su nacimiento en la segunda mitad del siglo XVIII. El primero lo vincula con la actividad artística que llevaban a cabo los mimos en Grecia -que luego evolucionaría a la pantomima y el mimodrama- y con la atelana en Roma. La atelana es una representación con caricaturas, payadas, sátiras y bailes, cuya técnica es la falta de técnica: la improvisación según el momento (Carella 29). El segundo resalta el carácter intermitente del sainete ${ }^{22}$ y ubica su origen en la intersección entre el ya existente sainete español y la tradición sainetera local (Pelletieri, El sainete y el grotesco criollo: del autor al actor 12). Ambos autores lo clasifican dentro de los géneros menores (en relación con el drama y la comedia), y apuntan el desdén y la marginalidad con las que fue recepcionado por la crítica y por los círculos legitimadores del arte.

Carella (17) define al sainete como una pieza teatral breve y jocosa que representa las actividades cotidianas del pueblo en un tono tragicómico; las fábulas que presenta pertenecen a los conflictos desatados en tres ambientes: la urbe, el campo y el arrabal. En su versión local, este género surgió durante la ola inmigratoria de principios del siglo XX, lo que selló su temática y conflictos en relación estrecha con las problemáticas suscitadas por el extranjero recién llegado y por la industrialización (la vida en los conventillos, la calle, el barrio y el trabajo). A su vez, incluye temas universales como la soledad, la muerte, el abandono, el crimen, la promiscuidad y las desigualdades sociales, y utiliza la improvisación y la creación/deformación de los lenguajes a través de sílabas que se ligan o de palabras dislocadas.

22 A partir de aquí hacemos referencia al sainete criollo, que se diferencia del sainete español, en donde tuvo su origen, porque incorporó a sus temáticas y lógicas las problemáticas propias del criollo rioplatense de principios de siglo. 
Carella también vincula el sainete a la idea de pueblo y a su necesidad de expresión; si bien sus reflexiones no tienen rigurosidad en cuanto a qué relaciones son las que se establecen dentro de las "culturas populares", les adjudica la utilización del sainete. El autor recrea un clima de época en donde frente al cuasimonopolio de las compañías teatrales extranjeras, era necesario y urgente crear un teatro vernáculo que hablara sobre las problemáticas locales (Carella 12-7). Pelletieri también considera esta premura por construir un teatro nacional como un elemento que se destacaba en las producciones de fines del siglo XIX en los teatros porteños. No puede dejar de mencionarse dentro de estas experiencias la que fue considerada la primera obra teatral vernácula, Juan Moreira (1884), estrenada por la primera compañía nacional, Los Podestá. Aquella pieza, inspirada en la novela del escritor argentino Eduardo Gutiérrez, fue un éxito rotundo, debido a lo cual fue recuperada con posterioridad para su reescritura en lenguaje cinematográfico.

Pelletieri establece una relación indisociable entre el sainete y el grotesco, porque sitúa el surgimiento del último sobre las cenizas del primero. Si bien no retomaremos la clasificación que construye el autor en torno al desarrollo del sainete ${ }^{23}$, es interesante tener presente que existen elementos comunes y cierta continuidad entre el sainete y el grotesco. Este último, creado por el director teatral y dramaturgo Armando Discépolo, se organiza a partir de la caricatura patética y su relato le otorga importancia a las voces de todos los personajes (no como en el sainete, que se le concede solo a la pareja de criollos), de modo que cada uno tiene su verdad, por lo que existe una verdad general relativa. Busca lo nuevo pero recurre también a lo viejo, parodia las relaciones sociales y mezcla procedimientos (Pelletieri, "La puesta en escena argentina de los '80: Realismo, estilización y parodia” 184-7).

La comedia del arte comparte algunos elementos con el grotesco y el sainete. Para Carella, "el sainete casi llega a ser una continuación de la comedia del arte" (26). Esta forma teatral, que se desarrolló en Italia entre los siglos XVI y XVII, era una representación que se hacía en la plaza, donde se improvisaban actuaciones relacionadas con la vida cotidiana y las dificultades del pueblo. Los primeros cómicos pertenecían a los sectores pobres y mezclaron varios dialectos, con lo que crearon el grammelot, un idioma entendido por todos. Al principio solo protagonizaban las escenas los hombres, que vestían una máscara que tapaba su rostro, lo que le otorgaba mayor importancia al lenguaje corporal, cargado de movimientos y saltos bruscos. Cuando se incorporó la mujer en la representación se eliminaron las máscaras (para que pudieran verse los rostros de las jóvenes), se introdujo la temática del amor y mejoró la dramaturgia.

Si observamos la estética del teatro comunitario podremos identificar muchos elementos del sainete, el grotesco y la comedia. Por un lado, la temática de la inmigración

23 Pelletieri (34-94) identifica tres fases del sainete: la primera, el sainete como pura fiesta, está estructurada sobre la base de una obra caricaturesca pero sentimental, con una trama melodramática y un final feliz. La segunda, denominada fase secundaria o canónica, asiste a la profundización del conflicto del inmigrante y adquiere un tono más tragicómico. En la tercera, donde el sainete evoluciona hacia el grotesco, se difuminan muchas de las primeras características para dar lugar a una obra en la que se mezcla lo moderno con lo tradicional, y desaparece el clima festivo del primer tipo. 
es utilizada por muchos de los grupos ${ }^{24}$ : en la reconstrucción del pasado de la comunidad es parte fundamental el suceso de la gran inmigración, ya que es innegable la influencia del crisol de razas en los procesos nacionales posteriores. Por ese motivo, muchas de las obras de teatro comunitario reconstruyen la época del conventillo y las problemáticas idiomáticas entre italianos, franceses, turcos, rusos y españoles.

También se retoma el tono burlesco y de parodia, y se crean estereotipos exagerados del cocinero, el verdulero, la mujer ama de casa, la abuela y diversas figuras de la idiosincrasia de la clase media. Algunos grupos, como el de Barracas o Los Cruzavías (partido de Nueve de Julio, provincia de Buenos Aires), interpelan desde sus obras problemáticas más ligadas a las desigualdades sociales, la pobreza, la marginalidad. Otras se encargan de manifestar demandas por cuestiones concretas como falta de infraestructura edilicia, invasión de construcciones que quebrantan el espacio público del barrio, falta de recursos en la salud o la educación de la comunidad. Pero el elemento común que se vincula con los géneros del sainete, grotesco o comedia del arte, lo encontramos en que las problemáticas representadas son aquellas que aquejan al barrio o a los vecinos de una comunidad determinada, o son sucesos de su historia como barrio/ciudad/pueblo.

Por otro lado, en este teatro se observa una deformación del lenguaje análoga a la que planteaban los autores en los géneros analizados (giros idiomáticos, lunfardo, etcétera), la utilización del espacio público y la improvisación del modo, aspectos que se pueden ver en la comedia del arte y que son factores fundamentales para describir y pensar sobre la estética comunitaria. Por último, destacamos con Carella la importancia que adquiere el hecho de que "el pueblo pueda verse a sí mismo en el escenario", porque esa es la característica distintiva del teatro comunitario: los vecinos representan ellos mismos su propia historia.

\section{2.g.2. Otros antecedentes}

Bidegain (54) afirma que el teatro comunitario posee características del teatro tosco: tipos genéricos, pensamientos aparte, reflexiones tópicas, chistes de alusión local, utilización de los imprevistos, las canciones, los bailes, el ruido, prótesis, accesorios, peinados y maquillajes saturados.

Según las definiciones que Pavis (477) realiza del teatro popular y el teatro de calle, el teatro comunitario también comparte con ellos la utilización del espacio público como lugar de representación, en contraposición con el escenario a la italiana. Podríamos sumar a este paralelismo entre ambos tipos de teatro la conceptualización que hace Judith Weiss (cit. en Proaño, Teatro comunitario, belleza y utopía 266) de teatro popular, y allí encontrar nuevos elementos compartidos, como que ambos poseen una organización alternativa, el control de la producción y del material artístico, la organización en un modo no jerárquico

24 Grupo de Teatro Comunitario de Berisso, Grupo de Teatro Popular de Sansinena, Grupo Catalinas Sur, Grupo Patricios Unidos de Pie, entre otros. 
y el énfasis en los procesos colectivos (Proaño Gómez, Poéticas de la globalización en el teatro latinoamericano 266).

Otros antecedentes estéticos del teatro comunitario se pueden rastrear en el teatro filodramático, en las primeras manifestaciones de teatro independiente, en las formas de teatro anarquista y en el agit prop (Bidegain 19). Proaño Gómez (Teatro comunitario, belleza y utopía 266) señala, por un lado, que el teatro comunitario comparte con los grupos de los años sesenta y setenta la particularidad de que corporizan la voz de una mayoría marginada y expresan una visión de mundo contrahegemónica, y por el otro, que apelan a recursos retóricos de la expresión teatral performativa (vestuario, gestualidad, colores, canciones, sonidos, luces), que tienen mayor poder que la palabra escrita.

Si bien esta estética retoma géneros populares, Scher (103-7) hace hincapié en que el teatro comunitario resignifica y dialoga con géneros populares, pero no los aborda arqueológicamente. Tanto Scher como Proaño Gómez proponen prestar especial atención a la función que cumple el canto, el coro, como una de las dimensiones más intensas en el trabajo de la dramaturgia. Utiliza el humor, la parodia y la ironía para abordar las temáticas, nunca el drama psicológico. También son fundamentales los apoyos musicales, basados principalmente en la murga.

Muchos de los grupos aún están buscando potenciar la plástica, entendida como la construcción del espacio escénico (escenografía, utilería, vestuario, iluminación). Pero para hacerlo es necesario disponer de un espacio propio de trabajo, con el cual cuentan solo unos pocos grupos.

\section{2.h. La Red}

Los grupos de teatro comunitario de Argentina están nucleados en la Red Nacional de Teatro Comunitario ${ }^{25}$, la que a su vez se inserta en la Red Latinoamericana de Arte para la Transformación Social. El nacimiento de esta última se concretó en 2003 gracias a una iniciativa de la Fundación Avina, organismo creado por el empresario suizo Stephan Schmidheiny en 1994 y que "trabaja en la búsqueda del desarrollo sostenible de América Latina fomentando la construcción de vínculos de confianza y alianzas fructíferas entre líderes sociales y empresariales, y articulando agendas de acción consensuadas" (Fundación Avina).

Greco (20-1) enumera cuatro rasgos organizativos propios de la Red:

- La dimensión horizontal de las relaciones entre los diferentes elementos de la Red (puntos nodales).

25 La Red Nacional de Teatro comunitario se conformó con el fin de construir un espacio colectivo de transmisión de experiencias, información y saberes. Tiene reuniones mensuales en las que participan todos los grupos, e intenta trasladar las mismas lógicas de funcionamiento de los grupos de teatro comunitario en cuanto a la solidaridad, la horizontalidad y la construcción conjunta. 
-La prevalencia de relaciones de intercambio entre los puntos nodales.

-El desarrollo de actividades de coordinación de parte de la Red.

-El empleo de nuevas tecnologías comunicativas para coordinar las actividades y los flujos de información.

Las dificultades que surgen se vinculan con la inclusión de esta Red en el sistema socioeconómico, con la visibilidad obtenida hacia afuera de la Red y con la cobertura económica. Greco (21) señala que tanto la visibilidad como el financiamiento son claves para definir los niveles de autonomía, y que es fundamental para la instalación y el desarrollo de la Red el impulso de redundancias informacionales, es decir, la circulación/ propagación concéntrica de información fuera de la red, al igual que la difusión de los resultados positivos que se van consiguiendo.

\section{2.i. Transformación social}

Sería interesante retomar un punto neurálgico que atraviesa todos los escritos sobre teatro comunitario, el de la transformación social.

Marcela Bidegain (63) ubica a la actividad teatral comunitaria en un lugar de resistencia hacia el poder establecido, ya que, articulados como un contrapoder, los vecinos elaborarían proyectos contrahegemónicos que cuestionan los conceptos de arte y política existentes. Por su parte, Scher (87) afirma que el teatro comunitario sacude paradigmas que parecen inmutables, que pone la mirada sobre lo que pasa desapercibido y que abre un espacio donde el que lo requiera puede desarrollar su creatividad, con lo que se transforman el espacio y los cuerpos. Para Proaño Gómez (El desplazamiento de la política: teatro comunitario argentino 3) las categorías que guían la práctica de los grupos se ciñen a ideas de la modernidad como identidad, pertenencia a una totalidad, conciencia colectiva, planteamientos utópicos. Esta autora afirma que los grupos de teatro comunitario desafían al capitalismo, al sistema económico neoliberal y buscan recuperar, a través de la intervención política, la capacidad de reescribir y modificar la historia.

Respecto del abordaje de la noción de "lo político", Proaño Gómez (El desplazamiento de la política: teatro comunitario argentino 8) considera que el teatro comunitario produce una inversión de la jerarquía de los valores neoliberales que se visualiza en la lucha por la no-privatización de los espacios públicos, la ruptura con la distinción entre lo público y lo privado, y la transformación del concepto de propiedad privada. Bidegain (61) resalta el hecho de que los grupos no nacen organizados por instituciones, sindicatos o partidos políticos, sino que se autoconvocan a partir de la exclusión, lo que colabora con la conformación de un nuevo sujeto colectivo.

Cuando un grupo de acción cultural pone en discusión discursos, estéticas, formatos y modos de circulación desde la autoconciencia, logra un proceso de producción de conocimiento. En este sentido, Proaño Gómez (Poéticas de la globalización en el 
teatro latinoamericano 8) visualiza el proceso como una lucha por la construcción de sentido que se expresa en las representaciones teatrales a nivel discursivo-gestual. Pero las investigadoras extienden esta transformación desde el nivel de las significaciones y la conciencia, a las prácticas de la vida cotidiana, ya que es allí donde se debaten las prácticas institucionalizadas (Bidegain, Marianetti, Quain y Cabanchik 30).

Sería interesante analizar a los grupos de teatro comunitario a la luz de la nueva coyuntura histórica, con sus actuales aperturas y clausuras. Y este punto es fundamental si reconocemos que desde 1983 los marcos en los que se encuadraban la economía, las políticas sociales y los proyectos políticos se han ido modificando, contribuyendo a la realineación de fuerzas, la apertura y el cierre de espacios de construcción política. Las prácticas culturales, y dentro de ellas el teatro comunitario, entramadas en los tejidos de estas transformaciones, instauraron nuevos vínculos y articulaciones.

El análisis del teatro comunitario argentino recién está comenzando en los ámbitos académicos de todo el país. Es necesario motivar la producción intelectual para dar cuenta de su potencialidad, sus tensiones y procesos internos dentro de una realidad social compleja como la argentina. Desde esa perspectiva, el presente trabajo intentó reconstruir un mapa de inicio del teatro comunitario argentino contemporáneo, a partir del cual crear puentes y conexiones con expresiones teatrales y artísticas pasadas. Se buscó generar un entramado de experiencias enmarcadas en procesos históricos, con la idea de dar un paso inicial en la profundización del estudio de este fenómeno a partir de casos concretos.

\section{Referencias}

Alonso, Luciano. "Modo de dominación y regímenes de violencia en las dictaduras iberoamericanas. Un esbozo de comparación”. e-l@tina. Revista electrónica de estudios latinoamericanos (2007). <http://iigg.sociales.uba.ar/files/2011/06/elatina20.pdf>. Fecha de ingreso: abril de 2011 Sitio web.

Alvarellos, Héctor. Teatro callejero en la Argentina (1982-2006). De lo visto, vivido y realizado. Buenos Aires: Madres de Plaza de Mayo, 2007. Medio impreso.

Bidegain, Marcela. Teatro comunitario, resistencia y transformación social. Buenos Aires: Atuel, 2007. Medio impreso.

Bidegain, Marcela, Mariana Marianetti, Paola Quain y Adolfo Cabanchik. Teatro comunitario: Vecinos al rescate de la memoria olvidada. Buenos Aires: Artes Escénicas, 2008. Medio impreso.

Borba, Juliano. "El teatro ocupa los espacios públicos: Las políticas de los imaginarios urbanos". Afuera 4(7) (2009). <http://www.revistaafuera.com/NumAnteriores/pagina. php? seccion $=$ PraxisUrbana\&page $=04$. PraxisUrbanas. Borba.htm\&idautor=77 $>$. Fecha de ingreso: diciembre de 2010. Sitio web.

Briski, Norman. De Octubre a Brazo Largo, 30 años de teatro popular en Argentina. Buenos Aires: Madres de Plaza de Mayo, 2005. Medio impreso. 
Carella, Tulio. El sainete. Buenos Aires: Centro Editor de América Latina, 1967. Medio impreso.

Carreira, André. El teatro callejero en la Argentina y en el Brasil democráticos de la década del '80. La pasión puesta en la calle. Rosario: Nueva Generación, 2003. Medio impreso.

Dacal, Enrique. Teatro de la Libertad. Teatro "callejero" en la Argentina, desde el movimiento grupal de los 80. Buenos Aires: Madres de Plaza de Mayo, 2006. Medio impreso.

Daconte, Eduardo. "El método de creación colectiva en el teatro colombiano". Latin American Theatre Review (1977). 91-7. Medio impreso.

Díaz, Silvina. "El teatro como ámbito de resistencia: identidad, inmigración y exilio". Amérique Latine Histoire et Mémoire. Les Cahiers ALHIM 18 (2009). <http://alhim. revues.org/index3301.html $>$. Fecha de ingreso: agosto de 2010. Sitio web.

---. "El modelo antropológico en el teatro emergente en Buenos Aires. El Apuntador". Revista de Arte Escénica. III Generación-Instituto Nacional del Teatro (2009). $<$ http://webiigg.sociales.uba.ar/iigg/jovenes_investigadores/4jornadasjovenes/EJES/ Eje\%204\%20Objetos\%20culturales\%20Arte\%20Estetica/Ponencias\%20eje\%204/ DIAZ\%20SILVINA.pdf $>$. Fecha de ingreso: agosto de 2010. Sitio web.

Dubatti, Jorge. El teatro de grupos, compañías y otras formaciones (1983-2002). Buenos Aires: Instituto Movilizador de Fondos Cooperativos C.L., 2003. Medio impreso.

---. Teatro y producción de sentido político en la postdictadura. Buenos Aires: Ediciones del CCC, Centro Cultural de la Cooperación Floreal Gorini, 2006. Medio impreso.

Feierstein, Daniel. "Una discusión abierta: la violencia política en la Argentina y su peculiaridad genocida”. Hasta que la muerte nos separe. Poder y prácticas sociales genocidas en América Latina. Comp. Daniel Feierstein y Guillermo Levy. La Plata: Al Margen, 2004. 61-89. Medio impreso.

Fernández, Clarisa. "Procesos de memoria en el teatro comunitario argentino". Palos y Piedras 11 (2011). <http://www.centrocultural.coop/revista/articulo/230/procesos_de_memoria_en_el_teatro_comunitario_argentino.html $>$. Fecha de ingreso: diciembre de 2011. Sitio web.

---. "La transmisión de la memoria en el teatro comunitario argentino. El caso del Grupo de Teatro Popular de Sansinena". Question (2011). <perio.unlp.edu.ar/ojs/index. php/question/article/download/1212/1086>. Fecha de ingreso: diciembre de 2011. Sitio web.

---. "Grupo de Teatro Popular de Sansinena. Nuevos abordajes para su análisis". Latin American Theatre Review. En prensa. Aceptado durante junio de 2012. Medio impreso.

---. "Recuerdos, espejos y memorias en el teatro comunitario argentino contemporáneo. Memoria colectiva, identidades y espacio público en las prácticas del Grupo de Teatro Popular de Sansinena”. Tesis de Maestría en Ciencias Sociales. Universidad Nacional de La Plata, 2012. Medio impreso.

Fos, Carlos. En las tablas libertarias. Experiencias de teatro anarquista en Argentina a lo largo del siglo XX. Buenos Aires: Atuel, 2010. Medio impreso. 
Fundación AVINA. Sitio web de la Fundación AVINA. <http://www.avina.net/esp/>. Fecha de ingreso: 11 de abril de 2011. Sitio web.

Greco, Ángela. “Teatro comunitario en la Argentina y la Red Americana de Arte para la Transformación Social". Telón de Fondo 8 (2008). <http://www.telondefondo.org/ numeros-anteriores/numero8/articulo/170/teatro-comunitario-en-la-argentina-yla-red-americana-de-arte-para-el-cambio-social.html>. Fecha de ingreso: agosto de 2010. Sitio web.

Halbwachs, Maurice. "Fragmentos de la memoria colectiva”. Selección y trad. de Miguel Ángel Aguilar. Revista de Cultura Psicológica (1991). <http://ddd.uab.es/pub/ athdig/15788946n2a5.pdf>. Fecha de ingreso: marzo de 2010. Sitio web.

Heram, Yamila. “Teatro comunitario, teatro transformador”. Cuaderno de Trabajo 64, Ediciones del Instituto Movilizador de Fondos Cooperativos (2005). <http://www. centrocultural.coop/descargas/cuadernos-del-ccc/teatro-comunitario-teatrotransformador.html >. Fecha de ingreso: agosto de 2010. Sitio web.

Lvovich, Daniel y Jaquelina Bisquert. La cambiante memoria de la dictadura. Discursos públicos, movimientos sociales y legitimidad democrática. Los Polvorines: Universidad Nacional de General Sarmiento, 2008. Medio impreso.

Pavis, Patrice. Diccionario de teatro. Barcelona: Paidós, 1998. Medio impreso.

Pelletieri, Osvaldo. "La puesta en escena argentina de los '80: Realismo, estilización y parodia". Latin American Theatre Review (1991). 117-31. Medio impreso.

---. El sainete y el grotesco criollo: del autor al actor. Buenos Aires: Galerna, 2008. Medio impreso.

---. En torno a la convención y la novedad. Estudios de teatro argentino e iberoamericano. Buenos Aires: Galerna, 2009. Medio impreso.

Pianca, Marina. El teatro en nuestra América: un proyecto continental (1959-1989). Minneapolis: Institute for the study of Ideologies and Literature, 1990. Medio impreso.

Proaño Gómez, Lola. “Teatro comunitario, belleza y utopía”. Teatro memoria y ficción. Ed. Osvaldo Pelletieri. Buenos Aires: Galerna, 2005. Medio impreso.

---. Estética social y la aparición de lo político. Teatro comunitario y espacio urbano en espacios de representación. Madrid, España: Ediciones Proaño-Gómez, 2006. Medio impreso.

---. Poéticas de la globalización en el teatro latinoamericano. Universidad de California, Irvine: Colecciones Gestos, 2007. Medio impreso.

---. "El desplazamiento de la política: teatro comunitario argentino". Afuera 9 (2010). $<$ http://www.revistaafuera.com/articulo.php?id=61\&nro=9>. Fecha de ingreso: febrero de 2011. Sitio web.

Raimondi, Marta Mariasole. "El teatro como espacio de resistencia en la Argentina de la postdictadura”. Nuevo Mundo, Mundos Nuevos (2008). <http://nuevomundo.revues. org/37982>. Fecha de ingreso: agosto de 2010. Sitio web.

Red de Investigadores de Teatro Comunitario. Blog de investigadores de teatro comunitario. <http://investigadoresdetc.blogspot.com/>. Fecha de ingreso: 12 de marzo de 2013. Sitio web. 
Red Nacional de Teatro Comunitario. Sitio web de la Red Nacional de Teatro comunitario. Fecha de ingreso: 20 de mayo de 2013. <http://www.teatrocomunitario.com.ar/>. Sitio web.

Rizk, Beatriz. Creación colectiva, el legado de Enrique Buenaventura. Buenos Aires: Atuel, 2008. Medio impreso.

Rosemberg, Diego. Teatro comunitario argentino. Buenos Aires: Emergentes, 2009. Medio impreso.

Sava, Alberto. Desde el mimo contemporáneo al teatro participativo. La evolución de una idea. Buenos Aires: Madres de Plaza de Mayo, 2006. Medio impreso.

Schechner, Richard. Performance, teoría y prácticas interculturales. Buenos Aires: Libros del Rojas, 2000. Medio impreso.

Scher, Edith. Teatro de vecinos, de la comunidad para la comunidad. Buenos Aires: Colección Estudios Teatrales del Instituto Nacional del Teatro, 2010. Medio impreso.

Seibel, Beatriz. Historia del teatro argentino II, 1930-1956: crisis y cambios. Buenos Aires: Corregidor, 2010. Medio impreso.

Svampa, Maristella. La sociedad excluyente. La Argentina bajo el signo del neoliberalismo. Buenos Aires: Taurus, 2005. Medio impreso.

Trastoy, Beatriz. "En torno a la renovación teatral argentina de los años '80". Latin American Theatre Review (1991). 93-100. Medio impreso.

Verzero, Lorena. "Teatro y militancia: del intelectual sartreano al intelectual revolucionario”. En torno a la convención y la novedad. Ed. Osvaldo Pelletieri. Buenos Aires: Galerna, 2009. 285-293. Medio impreso.

Weiss, Judith y Leslie Damasceno. Latin American Popular Theater. Alburquerque: University of Mexico Press, 1993. Medio impreso. 